\title{
Elecciones, partidos y conflicto social a finales de los años veinte del siglo $\mathrm{xx}$ en Rosario (Argentina)
}

\author{
Elections, Parties and Social Conflict \\ in the Late Twenties of the Twentieth \\ Century in Rosario (Argentina)
}

\author{
Oscar Rubén Videla \\ (D) 0000-0003-0167-5301 \\ Escuela de Historia \\ Universidad Nacional de Rosario-Conicet, Argentina \\ orvidela@gmail.com
}

Resumen: A finales de los años veinte, el régimen electoral municipal de la ciudad de Rosario (Argentina) sufre una notable transformación: pasa abruptamente de ser un régimen sostenido en la tributación a otro de amplia representación popular. Las circunstancias políticas, pero puntualmente la conflictiva situación social en que se produce, agregan un componente central a la coyuntura. En este sentido, es nuestra intención mostrar cómo responden los actores políticos (en particular los partidos) a las condiciones que imponen las novedades institucionales, aunque también nos interesa hacer evidentes las articulaciones entre conflicto obrero y política, mostrando cómo los enfrentamientos de clases ponen en situación buena parte de los ejes con los cuales aquellos actores pretenden construir legitimidad política a través de las urnas.

cómo citar: Videla, O. R. (2019). Elecciones, partidos y conflicto social a finales de los años veinte del siglo xx en Rosario (Argentina). Secuencia (104), e1392. DoI: https://doi.org/10.18234/secuencia. v0i104.1392 
Palabras clave: elecciones; partidos políticos; conflicto social; Rosario; Argentina.

Abstract: In the late twenties the municipal electoral system of the city of Rosario (Argentina) undergoes a remarkable transformation, passing abruptly from one sustained by taxation to one of popular representation. Political circumstances, but specifically the conflictive social situation in which it happened adds a central component to the conjunction. In this sense, it is our intention to show how political actors (especially parties) responded to the conditions imposed by institutional developments, but we also want to make clear the links between labor conflict and politics, showing how class confrontations showcased many of the cores with which those political actors sought to build political legitimacy through the ballot box.

Keywords: elections; political parties; social conflict; Rosario; Argentina.

\section{INTRODUCCIÓN}

Rosario era para finales de los años veinte del siglo xx una de las ciudades R más importantes de la Argentina. Con poco más de 400000 habitantes, era la segunda con más población detrás de la capital de la nación (Buenos Aires) y contaba con una intensa actividad económica estrechamente vinculada al modelo agroexportador. Pero la ciudad también había sido, y era, un campo de experiencias sociales y políticas; en ella se había arraigado una cultura política donde la intensa capacidad de movilización social de sus actores era una norma episódica pero recurrente (Bonaudo, 2006). No es casualidad que desde finales del siglo xIx e inicios del xx los movimientos político-partidarios de mayor arraigo local (radicales y demoprogresistas) habían debatido acerca de cómo articular intereses sociales en clave política; de allí que la cuestión electoral (calidad del votante, sistema de representación, etc.) había estado en el tapete en múltiples ocasiones. 
Ahora bien, en el transcurso de un año (para ser más precisos, de noviembre de 1927 a noviembre de 1928), la ciudad de Rosario pasó por seis procesos electorales (dos provinciales, uno nacional y tres municipales). La disputa a nivel nacional, en un primer análisis, parece no tener mayor significado político que el de confirmar una tendencia ya indicada por la bibliografía sobre la coyuntura, el llamado "plebiscito" al ex presidente Hipólito Yrigoyen en abril (Horowitz, 2015; Rock, 1977); por su parte, las disputas a nivel municipal (noviembre de 1927 y abril y noviembre de 1928) y provincial (febrero y abril de 1928) no sólo son encarnizadas, sino que en ellas se hace evidente (en muy distinto grado y con algunas particularidades) el entramado de estas compulsas con el contexto de altísima conflictividad social por la que atraviesa la ciudad. En esta circunstancia, algunos de los objetivos que propongo dilucidar en este trabajo son, por una parte, caracterizar el comportamiento del sistema de partidos local ante las novedades institucionales que supone la ampliación del sufragio que pasa de un modelo fiscal sostenido en la figura del contribuyente urbano a otro de voto "universal". Por la otra, postulamos que el vínculo (tanto práctico como discursivo) que los distintos actores políticos establecen con los trabajadores es sin dudas uno de los ejes sobre los que se montan tanto los argumentos como las detracciones entre aquellos que pretenden construir legitimidad política a través de las urnas.

\section{LAS NOVEDADES DEL NUEVO RÉGIMEN ELECTORAL MUNICIPAL}

El tema de los fundamentos de la representación política municipal tenía en Argentina una larga tradición de debates que se remontaba a los clásicos en la formulación del sistema político argentino de mediados del siglo xIX (Sarmiento, Alberdi, etc.) (Ternavasio, 1991). ${ }^{1}$ El punto clave del debate había es-

${ }^{1}$ El predominio de la concepción alberdiana que otorgaba derechos electorales en el ámbito municipal sólo a quienes lo sostuvieran con sus impuestos, hizo que a lo largo de la segunda mitad del siglo xIx y las primeras décadas del siguiente, predominaran legislaciones electorales que restringían el voto a los contribuyentes (con diferencias internas a lo largo del país), tal es así que aún en las tres más grandes ciudades argentinas (Buenos Aires, Rosario y Córdoba) recién pasaran a un régimen sostenido en el sufragio universal masculino con posterioridad a la primera guerra mundial (1918, 1928 y 1924, respectivamente). La circunstancia contrasta relativamente con otras experiencias latinoamericanas donde, restricciones similares para conformar el padrón de votantes municipales no inhibieron su potencial movilizador, 
tado en la condición del votante, donde claramente la opción por el sufragio universal no había sido la más extendida, no obstante que sí lo fue a nivel nacional y provincial (Bonaudo, 2006). En el ámbito municipal se pensaba que el sujeto de la representación debía ser el "vecino" más que el "ciudadano" y como corolario de ello se construyó un discurso "antipolítico" contraponiendo a esta (la política) con la "administración" (Ternavasio 1989, 1996). Ahora bien, en el específico contexto rosarino, el tema de la representación municipal se articuló claramente sobre dos ejes mutuamente imbricados: las condiciones de la participación política de los extranjeros y los derechos que debían otorgar la tributación a los habitantes de la ciudad. En estos términos, a lo largo de la segunda mitad del siglo xIx y hasta precisamente la coyuntura analizada, esta convicción dio lugar a un sistema electoral calificado por el cual se constituía el poder legislativo municipal expresado en el Concejo Deliberante (en adelante CD). ${ }^{3}$ La condición de contribuyente definió la po-

aunque la circunstancia no impidió progresivamente menores grados de autonomía de la instancia municipal respecto de otros niveles del estado a lo largo del siglo xIX. Para un más que interesante intento comparativo entre Argentina y México, véase Moyano (2006); para el caso chileno centrado más en la problemática del fraude, véase Ponce de León Atria (2015).

${ }^{2}$ El tema de la ciudadanía ha sido objeto de una extensa y fructífera reflexión en el campo de la historiografía latinoamericana acerca de las formas concretas (históricamente determinadas) de la representación política, circunstancia que ha puesto a debate esta distinción ciertamente tajante entre vecindad y ciudadanía, haciendo hincapié en la elaboración de propuestas que tratan de explicar no sólo los solapamientos entre ambas, sino particularmente tratar de penetrar en cómo los actores sociales experimentaron la política. Para un panorama historiográfico (necesariamente incompleto) son interesantes los análisis de Aguilar Rivera (1998), Irurozqui (2007), Monsalvo Mendoza (2009) para México, o Ragas Rojas (2006) para Perú.

${ }^{3}$ Las constituciones santafesinas del periodo previeron un régimen municipal de gobierno de relativa autonomía compuesto por una rama ejecutiva (normalmente individual, el intendente) y otra legislativa compuesta por una cantidad variable, según la población total, de concejales elegidos por los vecinos/contribuyentes que se renovaban por mitades tal como era una tradición desde mediados del siglo xIX en las legislaturas, tanto nacional como provinciales. Sus funciones variaron a los largo del periodo, pero en general los CD conservaron la capacidad, a través de ordenanzas, de crear rentas, tasas, patentes, permisos y de imponer multas con los cuales solventar las finanzas locales, además de controlar las finanzas municipales, la regulación edilicia, la circulación, las pesas y medidas, la salubridad e higiene, los espectáculos, etc.; en un principio podían (a propuesta del ejecutivo) nombrar y remover a los empleados de la administración, capacidad que sólo conservaron para los de su inmediata dependencia; enmarcados en una ley provincial que dictaba también su propio reglamento electoral, podían aceptar, rechazar y juzgar a sus miembros, y en ocasiones suspender, acusar o pedir la destitución del titular del ejecutivo municipal. La designación del poder ejecutivo municipal estuvo desde 1890 a cargo del poder ejecutivo provincial hasta la reforma constitucional de 1962, con el brevísimo interregno entre 1933 y 1935 (Ensinck, 1970). El panorama del poder local no estaría 
testad de ser elector y elegido, y si bien con variaciones en ese lapso, el CD fue indudablemente un espacio de representación de las distintas fracciones de la burguesía comercial rosarina; en este sentido, el listado de concejales era un muestrario (incompleto por supuesto) de los líderes empresariales de la ciudad: de los más ricos y exitosos indudablemente, pero con el inicio del siglo también de aquellos que constituían la base electoral del sistema (los medianos y pequeños comerciantes) (Alarcón, 2013).

Ahora bien, en la coyuntura de apertura del sistema político argentino de principios del siglo $\mathrm{xx}$, los nuevos aires que trajeron la Intervención provincial (1911-1912) (Carrizo, 2005; Cecchini, 1991) y las ampliaciones del régimen electoral nacional (1912) (Botana, 1985; Castro, 2012), no se trasladaron normativamente al nivel municipal. ${ }^{4}$ No obstante, el clima político general que le siguió a la apertura política de 1912, y particularmente la larga hegemonía de las distintas facciones radicales en la provincia, ${ }^{5}$ hizo que, por una parte, las disputas entre estos y la Liga del Sur (casi inmediatamente constituido como Partido Demócrata Progresista [PDP en adelante]) se hicieran endémicas, pero también que se extendieran una multitud de mecanismos para controlar los resultados de las elecciones sobre una base electoral que se expandiría más lentamente.

Ahora bien, el dato que más resalta de la reforma del sistema electoral introducido por la nueva Ley Orgánica de Municipalidades (núm. 2147, sancionada en septiembre de 1927), es precisamente la expansión de los votantes a nivel municipal. En la última elección con padrón de contribuyentes (noviembre de 1927) votaron entre 3149 y 5566 personas según ganadores

completo sin la mención del jefe político (en la coyuntura se ha cambiado recientemente el título al de jefe de policía), nombrado directamente por el ejecutivo provincial en cada uno de los departamentos en los que se divide la provincia (Rosario es la cabecera del Departamento homónimo) es su representante directo y durante años responsable del manejo político (y por tanto electoral) y del orden social (urbano y rural). Para el siglo xix ha sido trabajado por Marta Bonaudo (2008), faltando un estudio de igual magnitud para el siglo xx.

${ }^{4}$ Contrasta en este sentido con la evolución en la principal ciudad de la Argentina, Buenos Aires, donde las iniciativas son inmediatas y se concretan con relativa rapidez en 1917 con la Ley núm. 10240 (Privitellio, 2003). La otra gran ciudad argentina, Córdoba, también tardíamente adoptó el sufragio universal masculino en 1924 (Moyano, 2006, p. 65; Vidal, 2000, p. 185).

${ }^{5}$ Luego de la derrota en las elecciones provinciales de 1912 los partidos conservadores santafesinos se diluyen rápidamente, de allí en adelante (más allá de las intensas luchas de facciones) los radicales gobernaron ininterrumpidamente la provincia desde 1912 hasta el golpe de 1930 bajo diversas denominaciones: Unión Cívica Radical, Unión Cívica Radical de Santa Fe, Unión Cívica Radical Unificada, Unión Cívica Radical (Comité Nacional) (Karush, 2006). 
o perdedores. ${ }^{6}$ Para la primera elección con el nuevo sistema el número fue multiplicado diez veces y siguió creciendo con el tiempo. Una evolución similar ocurre con los padrones, en las elecciones precedentes las inscripciones no habían pasado de entre 4000 o $5000,{ }^{7}$ en las subsiguientes no bajaron de los 54000 (véanse cuadros 1 y 2).

La expansión es producto de la nueva ley que establece una nueva base de la representación sostenida en el voto obligatorio y universal, tomando a los efectos el padrón provincial vigente (es decir, compuesto por todos los hombres, nativos, mayores de 18 años).

Ahora bien, respecto del voto de los extranjeros, la nueva ley es más inclusiva que el sistema previo, aunque a diferencia de aquel no hace obligatorio el voto luego de la inscripción al padrón: ${ }^{8}$ pueden votar aquellos extranjeros mayores de edad que ejerzan alguna profesión liberal; los contribuyentes (del municipio o de la provincia) por sumas mayores a los 50 pesos anuales, pero también los que estén casados con nativas con uno o más hijos argentinos. ${ }^{9}$

La nueva representación que esto supone merece que introduzcamos algunas indicaciones respecto del peso relativo del voto extranjero ( $\mathrm{y}$ nativo) en Rosario que contrasta con el sentido común historiográfico que asignaba un papel clave al voto de los extranjeros en la esfera municipal. Si bien las

${ }^{6}$ La votación es efectivamente escandalosa por la aplicación de mecanismos claramente cuestionables por los dos partidos en disputa: el PDP con control efectivo del CD y por tanto de la Junta Electoral, y la Unificación Comunal Radical (expresión a nivel municipal de la UCR Unificada) que controla el ejecutivo municipal y por esa vía las mesas de inscripción. En el escrutinio la mayoría de la Junta Electoral anula 16 mesas por supuestas irregularidades, quedando válidas sólo 23. Los radicales unificados impugnan afirmando que fueron tachados 1470 contribuyentes. Contabilizando las mesas impugnadas suman aproximadamente 2000 votos más. Los radicales unificados constituyen el $\mathrm{CD}$ aparte y entablan conflicto político y legal que mantienen hasta las vísperas de las elecciones de abril de 1928. Los radicales yrigoyenistas no participaban de las elecciones municipales, en la coyuntura con los mismos argumentos que los socialistas: por la ausencia del sufragio universal. La estrategia de la mayoría demoprogresista de finales de 1927 no se limitó al control del escrutinio, sino que previamente había reformado el reglamento electoral, estableciendo la distribución proporcional de los concejales en reemplazo del sistema de lista incompleta con la evidente intención de incluir a potenciales aliados en el CD (el Centro "La Propiedad) así como alentar a otras facciones radicales opositoras a los unificados de manera de fragmentar la potencial oposición radical.

${ }^{7}$ Son cifras introducidas por los mismos concejales en un debate y que todos dan por certeras. Concejo Deliberante de Rosario, Diario de Sesiones, 2 de septiembre de 1927.

${ }^{8}$ Provincia de Santa Fe (1928), art. 56.

9 Esta última condición era una vía de ampliación de la participación de los extranjeros no contribuyentes, pero que como podemos inferir de las inscripciones no fue utilizada por los potenciales beneficiarios. 


\section{Cuadro 1. Elecciones del Concejo Deliberante: cantidad de votantes (1927-1929)}

$\begin{array}{ccccc} & 27 \text { de noviembre de } & 29 \text { de abril } & 11 \text { de noviembre } & 10 \text { de noviembre } \\ \text { Elección } & 1927 & \text { de } 1928 & \text { de } 1928 & \text { de } 1929\end{array}$

Votantes Entre 3149 y $5566 \quad 34018 \quad 42200 \quad 40484$

Fuente: Municipalidad de Rosario, Concejo Deliberante, Diario de Sesiones, 28 de noviembre de 1927; La Capital, 11 de mayo de 1928; La Acción, 8 de mayo de 1928; Santa Fe, 17 de noviembre de 1928; La Acción, 17 de noviembre de 1928; El Orden, 15 de noviembre de 1929; La Acción, 15 de noviembre de 1929. Las cifras no coinciden en todas las fuentes para una misma elección con diferencias de 410 (1929), 2 (11 de noviembre de 1928) y 16 (29 de abril de 1928). Se tomó como criterio consignar los valores más altos.

\section{Cuadro 2. Inscritos a los padrones municipales}

$\begin{array}{ccc}29 \text { de abril } & 11 \text { de noviembre } & 10 \text { de noviembre } \\ \text { de } 1928 & \text { de } 1928 & \text { de } 1929\end{array}$

$\begin{array}{lrrr}\text { Diez secciones urbanas } & 43942 & 55332^{\mathrm{a}} & 55411^{\mathrm{a}} \\ \text { Suburbios } & 9882 & & \\ \text { Extranjeros y Mujeres } & 818^{\mathrm{b}} & \text { ca. } 839^{\mathrm{c}} & \mathrm{ca} .909^{\mathrm{d}} \\ \text { Total } & 54642 & 56171 & 56320\end{array}$

${ }^{a}$ En la fuente no están discriminados las secciones de suburbios.

${ }^{\mathrm{b}}$ Según indica La Acción a la fecha del cierre del padrón (21 de diciembre de 1927), este está constituido por 815 extranjeros y sólo 28 mujeres, dando un total de 843 .

${ }^{c}$ Calculado sobre las diferencias consignadas entre el total de inscritos y el total del padrón provincial.

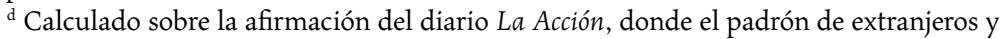
mujeres se incrementó a 70 en comparación con el anterior.

Fuentes: La Capital, 29 de abril de 1928; La Acción, 12 de noviembre de 1928; La Acción, 9 de noviembre de 1929.

fuentes no nos aportan cifras exactas, son suficientes para indicar que, por una parte, los extranjeros constituyeron cuanto mucho una cuarta parte del padrón de contribuyentes, por lo que la participación de los nativos debía ser central en la constitución de una buena elección municipal en el anterior sistema. Por otra parte, es indudable que la condición de extranjero pasó a ser 
insignificante a partir de la reforma, por lo que debemos suponer que "viejas" formas de prácticas políticas si bien no llegaron a su fin, no constituían a partir de este momento una parte tan central de las mismas; nos referimos tanto a las más informales que se articulaban a través del muy dinámico asociacionismo inmigrante, como a las más estrictamente formales evidenciadas en la participación directa de corporaciones empresariales (los ejemplos más evidentes son la sociedad de almaceneros o la asociación de propietarios inmobiliarios) donde el componente extranjero era muy significativo.

Si bien mucho más acotado, los resultados de la inclusión del voto femenino calificado merecen unas consideraciones: la más obvia la indican los números y es el rotundo fracaso de la participación femenina; evidentemente no se inscribieron mujeres, pero también es evidente que los partidos no tuvieron ninguna política concreta para alentar su participación, es más, podría indicarse que tampoco la prensa local insistió en demasía sobre el asunto. ${ }^{10}$

La posibilidad del voto femenino ya estaba prevista en la vetada Constitución de 1921, la cual habilitaba a las mujeres para votar y ser candidatas, aunque uno de los requisitos era ser mayor de edad y que "tengan la libre administración de sus bienes o diploma que las habilite para ejercer alguna profesión liberal". ${ }^{11}$ La nueva legislación, en su artículo 57, las excluía de ser candidatas, y sólo podían ser electoras aquellas que fueran mayores de " 22 años de edad y posean títulos universitarios que las acrediten para ejercer una profesión liberal; las profesoras normales nacionales de segunda enseñanza y

${ }^{10}$ Apenas algún comentario cuando la sanción de la ley que lo habilitaba, una foto (en un solo diario por otra parte) en las primeras elecciones (abril de 1928) y escasos comentarios posteriores, dan cuenta que no parecía ser parte de la agenda política. No obstante, tanto La Capital como La Acción le dedican algún espacio (aunque marginalmente) a las elecciones provinciales de San Juan donde debuta el voto universal femenino en la misma coyuntura, pero sólo a nivel informativo y sin mayores comentarios o posicionamientos; al respecto es interesante la polémica interpretación de Privitellio (2011) respecto de esta primera experiencia. En términos de posicionamientos el diario más explícito es La Acción, que en su editorial del 9 de abril de 1928 expresa sus reparos al voto femenino, indicando que "la masa femenina no esta todavía preparada entre nosotros como para actuar activamente en tales contingencias". Declarándose partidario de la propuesta calificada que impone la nueva ley santafesina. Por otra parte, es significativa la ausencia casi total (por lo menos en las fuentes consultadas) de la opinión de las propias mujeres, ya sea expresada individual o colectivamente a través de agrupamientos que ya existían en la coyuntura, algo de ello puede ser producto de la normal invisibilización de las mismas, pero también del escaso interés que supondría el voto calificado.

${ }^{11}$ Provincia de Santa Fe (1932). 
las que paguen impuestos a su nombre en comercios honestos, por una cantidad mayor a cincuenta pesos anuales". ${ }^{12}$

Un punto interesante sobre el voto femenino lo da el diario prorradical unificado La Acción, el cual transcribe en la primera página la carta que envía una mujer a su amiga, donde fundamenta su inscripción en el padrón respectivo. El tono es claramente indicativo del clima general y los límites en los que se concebía el voto femenino: la supuesta sufragante es indubitablemente una dama burguesa que pretende convencer a su amiga que es perfectamente posible conciliar las tareas del hogar con el voto municipal. ${ }^{13}$

\section{EL DESEMPEÑO ELECTORAL DE LOS PARTIDOS}

El partido político que pone más en juego con la nueva ley es el PDP. El CD de Rosario había sido desde la misma creación del partido como Liga del Sur (1908) uno de los ámbitos privilegiados en el accionar del mismo; indudablemente era un espacio de formación y proyección de liderazgos. Así, desde su recinto se habían construido carreras políticas notables en un cursus honorum que podía llegar tanto a la legislatura provincial como al Congreso nacional. A ello se sumaba que desde su primera intervención electoral en 1909 había conservado el control de la mayoría en el CD. Este había sido no sólo una de las principales herramientas políticas del partido en sus confrontaciones con las diversas facciones radicales, sino claramente "el último reducto" institucional del partido. Encarar un cambio tan profundo en el sistema de representación evidentemente ponía un velo de incertidumbre al partido, más en una

${ }^{12}$ Provincia de Santa Fe (1928).

13 "Te diré con toda franqueza que participo de tus opiniones en lo que se refiere a nuestra misión de dulzura en la tierra y tú misma puedes atestiguar que en mi hogar la alegría reina en soberana absoluta, que mis hijos son el objeto de mi constante preocupación y que mi dueño y señor no se ha quejado nunca de que le hubiera desatendido. Pero a pesar de esto y tal vez por esto mismo, que me considero una verdadera mujer, amante, cariñosa, honrada, pretendo que no se me puede negar el derecho que considero legítimo de contribuir con mi grano de arena al mejoramiento de la colectividad en cuyo seno actuamos. Creo, querida, que no es suficiente cuidar los hijos, impedir a las sirvientas que roben, y vestirnos bien para agradar a nuestros esposos. La vida debe tener para nosotras otros ideales y estoy segura que si en seno de un concejo deliberante las mujeres estuvieran representadas, la laboriosidad del conjunto sería considerablemente aumentada, la seriedad de las discusiones mejor observada y no se descendería nunca a los bajos ultrajes por respeto hacia las mujeres que del mismo formarían parte." La Acción, 20 de noviembre de 1927. 
coyuntura en la que, como veremos, no parecía contar con la voluntad de la mayoría de los rosarinos (véase cuadro 3).

Del análisis estricto de los resultados electorales se puede deducir que en el transcurso de poco más de un año el PDP pasa de una de sus peores performance electorales desde su creación (cuyo piso son indudablemente las elecciones provinciales de febrero de 1928) a un "resurgimiento" casi inmediato y una evidente consolidación para finales de 1929 que lo deja, según sus propias expectativas, con excelentes posibilidades para las elecciones legislativas nacionales de marzo de 1930 y con el horizonte abierto de cara a una futura elección para gobernador. ${ }^{14}$ No obstante un enfoque centrado en la escala local de la política muestra algunas disonancias con esta imagen: en principio, porque el PDP perderá definitivamente la mayoría del CD a manos de las heterogéneas facciones del radicalismo yrigoyenista, quedando no sólo muy lejos de cualquier control numérico (quorum, retiros, asistencia, etc.) del legislativo municipal, sino que su labor estará supeditada a establecer algún tipo de acuerdos con los ahora minoritarios radicales unificados $y / o$ aprovecharse de las constantes y continuas desavenencias de los yrigoyenistas. En términos generales, se hace evidente que el PDP superó con escasas dificultades el paso de un sistema electoral a otro a nivel municipal, por lo menos medido en términos de votantes, no así si lo miramos desde lo estrictamente institucional.

La reforma también fue considerada una oportunidad para los partidarios locales del catolicismo social. Estos si bien venían discutiendo la necesidad de crear un partido orgánico desde bastante tiempo atrás, hasta precisamente esta coyuntura habían optado por colocar a algunos de sus más expectables líderes en las listas del radicalismo (con una particular propensión por los unificados). ${ }^{15}$ Los católicos seguramente pensaron que el nuevo sistema electoral (que preveía la representación proporcional por cociente ${ }^{16}$ )

14 Para el clima al interior del partido en la coyuntura, véase Mauro (2013).

15 Para un tratamiento de la experiencia de la Unión Popular de Rosario, de sus antecedentes y postulados, véase Martín (2012, cap. 9).

${ }^{16}$ La representación proporcional por cociente a nivel municipal no era estrictamente una novedad en la coyuntura (se aplicaba también en la ciudad de Buenos Aires desde 1917), pero sí relativamente excepcional en el cuadro general de los legislativos argentinos, en particular por la amplitud de su aplicación: el cociente se extraía de dividir los votos válidos por la cantidad de cargos en disputa que a su vez se dividía por los votos de cada lista para obtener la cantidad de cargos logrados, los restos otorgaban cargos a las listas que superaban el cociente y luego a aquellas que hubieran alcanzado la mitad de este. No obstante, la interpretación de la distribución generó intensos debates. 


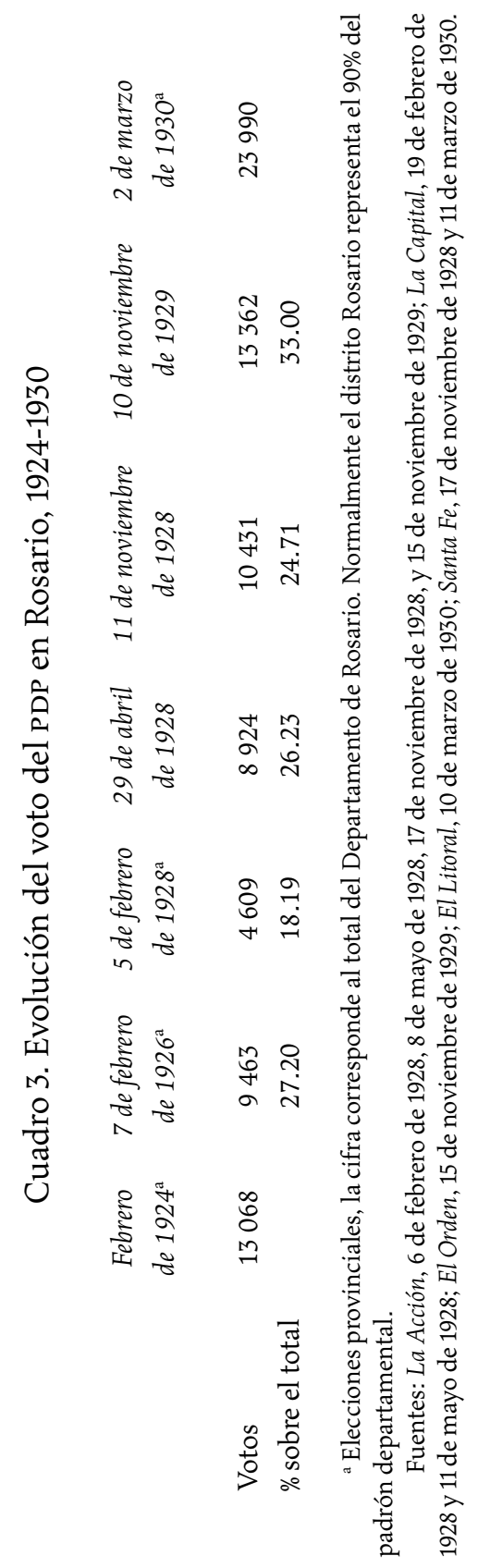


les permitiría en lo inmediato lograr algún representante y a partir de allí consolidar un electorado propio más claramente identificado con su doctrina. Para desazón de sus propulsores (el diario El Heraldo, el Círculo de Obreros, el obispado, etc.), la experiencia fue claramente fallida, después de una intensa campaña (con actos y mítines con presencia de líderes "nacionales" y una buena cobertura de la prensa ${ }^{17}$ ) la Unión Popular de Rosario (con apenas 712 votos, el 2\% del total) no llega siquiera a la mitad del cociente electoral (1427) que los ponga en la posibilidad de ingresar un concejal. Las elecciones de noviembre de 1928 confirman la tendencia (apenas superan el 1\% de los votos) haciendo que el partido se diluya y que los dirigentes católicos busquen nuevamente en los partidos mayoritarios un lugar para sus demandas.

Por otra parte, en el amplio y heterogéneo campo que siempre había sido el radicalismo santafesino, la expansión del electorado a nivel municipal es indudablemente una oportunidad para medir fuerzas, con el PDP, pero muy particularmente entre sus muchas facciones, circunstancia que se evidencia en la multiplicación de las listas que se identifican en esa tradición política.

En principio, es evidente que el radicalismo unificado es el sector más claramente en retirada. En un cuadro en el que la tendencia general será el crecimiento y la polarización de las facciones del radicalismo yrigoyenista, la Unión Cívica Radical Unificada -fuerza que gobierna la provincia desde 1924- está en franco retroceso: ya había estado en tercer lugar en las elecciones para diputados provinciales de 1926 con poco más de 9000 votos, se recuperó cuando trataba de conservar la gubernatura provincial en febrero de 1928 con poco más de 14000 votos, pero se vuelve a desplomar en las elecciones presidenciales y legislativas nacionales de marzo de ese año; pero donde el fracaso es sin dudas más evidente es a nivel municipal. Hasta las vísperas de la reforma, había conservado la minoría del CD con un caudal de votos ciertamente menor pero que podía atribuirse a lo restringido del padrón; no obstante un breve recorrido de su desempeño posterior (ya con un padrón ampliado) da como resultado inequívoco la decadencia de esta facción. En principio podemos atribuírselo al irrefrenable ascenso de los yrigoyenistas, pero posiblemente a que una buena parte de sus votantes migraran hacia el PDP, del cual sin dudas se diferenciaba escasamente, sea en la crítica común al "personalismo" de aquellos, como también en la ausencia casi absoluta de una interpelación "social" o siquiera popular de su discurso (véase cuadro 4).

17 En particular La Acción, pero también La Capital cubren sus actividades. 


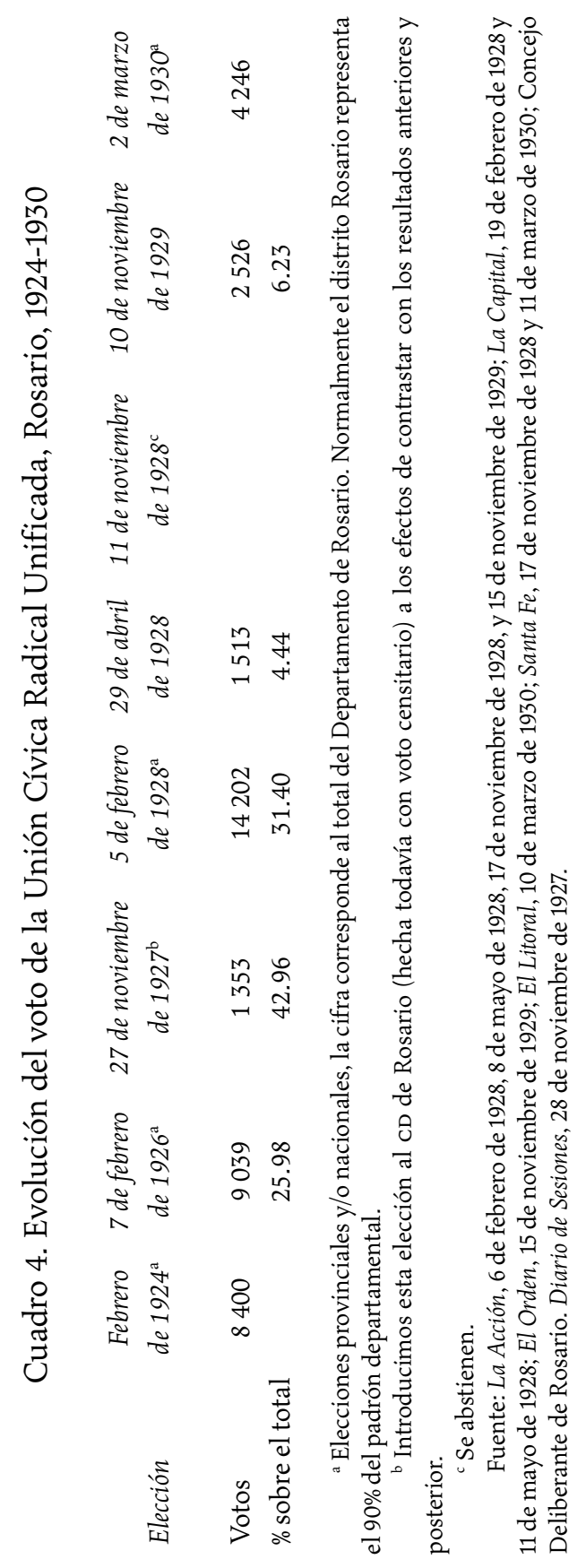


Un panorama totalmente inverso lo observamos en el radicalismo yrigoyenista. Ahora bien, una mirada que se abstraiga de la profunda conflictividad interna de los yrigoyenistas nos da como resultado un crecimiento al mismo tiempo notable y espasmódico. No obstante, esto no debe oscurecer la profunda impronta que la identidad radical tiene en el electorado rosarino: así, si sumamos a las cifras del cuadro 5 las de los también radicales unificados nos dan un resultado si no sorprendente, sí lo suficientemente importante como para llevarnos a reflexionar (en otra ocasión, por cierto) sobre la hegemonía casi absoluta de una identidad política en el sistema político local (véase cuadro 6).

No obstante, el rasgo definitorio del radicalismo rosarino es su fragmentación y el altísimo grado de conflictividad interna, circunstancia que provocará en cuestión de meses la polarización en dos orientaciones que se declaran igualmente yrigoyenistas y partidarias de los intereses de los obreros (veremos más adelante que es en grado diverso). Ahora bien, volviendo a la primera elección municipal bajo la nueva ley, esta da la oportunidad de que cada facción muestre su peso relativo, circunstancia que se hace evidente con sólo contrastar sus resultados (véase cuadro 7).

Sobre un total de 18 listas presentadas para la renovación total del CD (23 bancas), ocho corresponden a las listas radicales, y de estas siete son declaradamente "personalistas". La dispersión de estos últimos nos da indicios de cómo se construía el poder al interior de las facciones yrigoyenistas, todas ellas habían ido juntas dos meses atrás en las elecciones provinciales, pero la existencia del sistema proporcional, en un principio, las alentó a medir fuerzas sobre la base del control de situaciones partidarias, territoriales y hasta sectoriales (sean estos comités, seccionales, gremios y/o una combinatoria de estos); por otra parte, tanto el pobre desempeño del PDP en las elecciones provinciales (que podría hacer suponer que se repetiría en las municipales), como la seguridad de que el ejecutivo municipal también sería radical yrigoyenista (al ser elegido por el gobernador electo), posiblemente desalentaba las políticas unitarias.

Ahora bien, en el transcurso de pocos meses el panorama político (pero fundamentalmente social) cambiará sustancialmente. El resultado de ello será la creciente polarización de las facciones yrigoyenistas que se reducirán a tres para las elecciones de noviembre de 1928 y a sólo dos para las del año siguiente (véanse cuadros 8 y 9 ).

Se podría esgrimir razones sistémicas para explicar esta notable reducción, pero ni la fragmentación había sido ineficaz (de hecho cuatro de las siete 


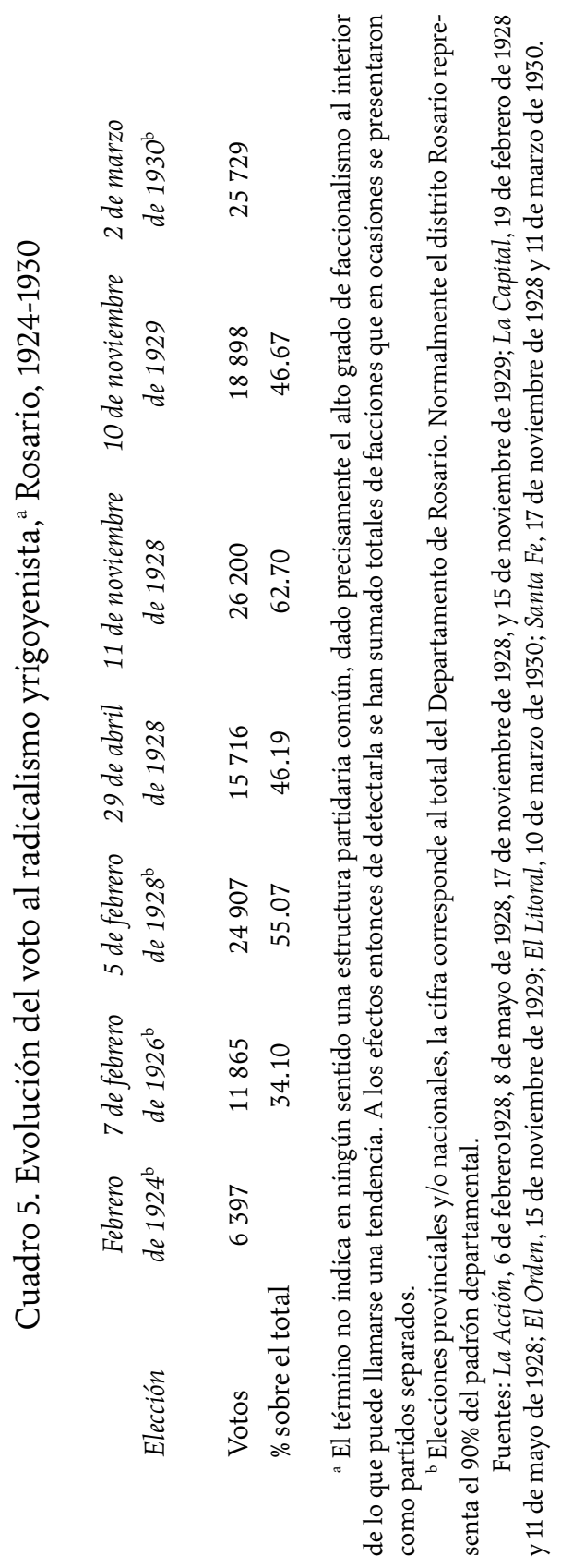




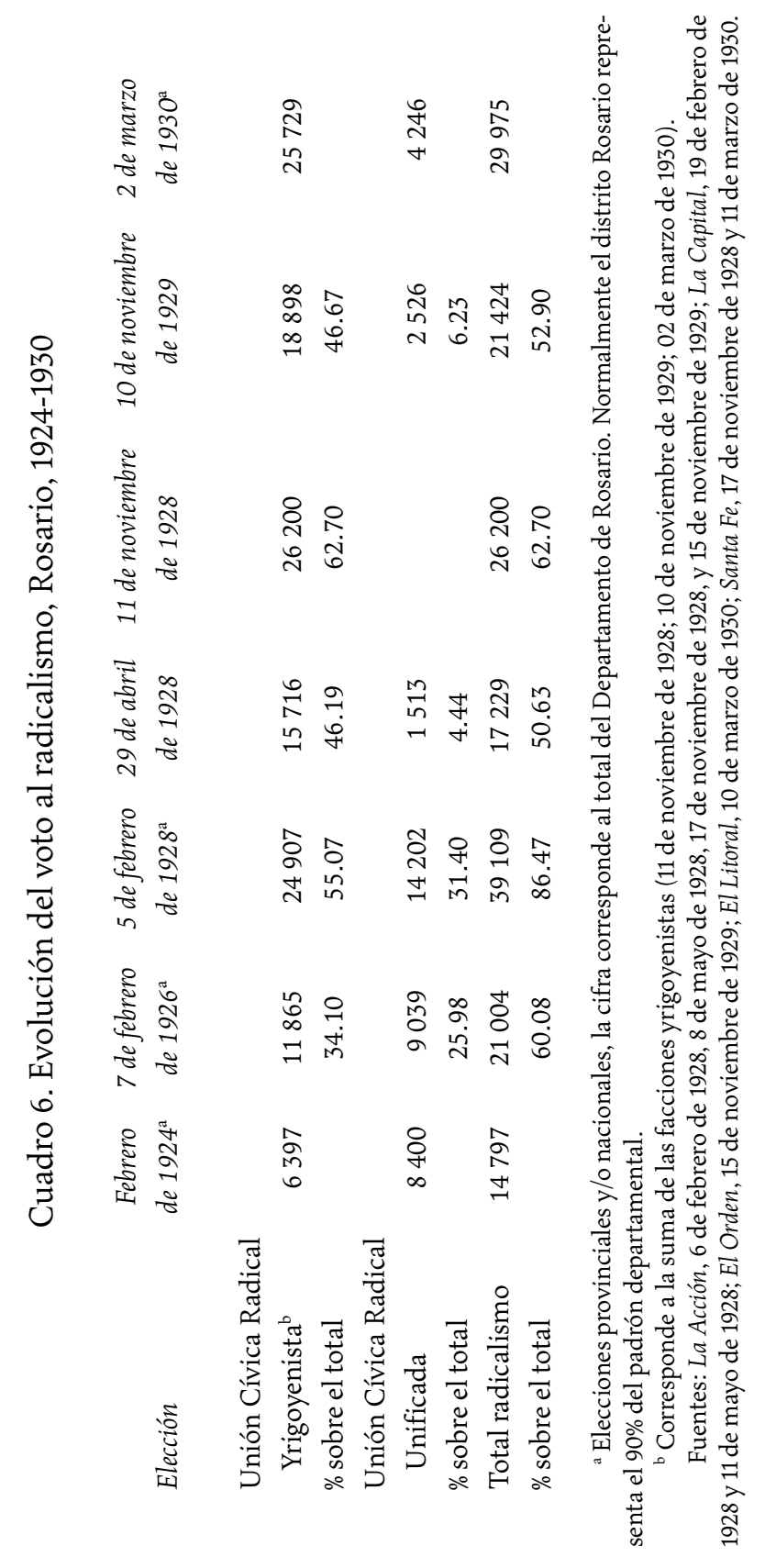


Cuadro 7. Elecciones del Concejo Deliberante (29 de abril de 1928)

Listas

Unión Cívica Radical

Partido Demócrata Progresista

Unión Radical Irigoyenista Pro Defensa

Comunal (Abalos)

Comité Hipólito Irigoyen (Cilvetti)

Unión Cívica Radical Unificada

Partido Socialista Independiente

Partido Comunista

Partido Unión Cívica Radical Irigoyenista

(Altieri)

Partido Socialista

Liga de Contribuyentes Centro "La Propiedad"

Unión Popular de Rosario

La Defensa Comunal

Federación de Comisiones Vecinales

Liga Ferroviaria y Marítima Yrigoyenista

Unión Vecinal Independiente

Liga Comunal Independiente

Agrupación Comunal Principista

Partido Comunal Irigoyenista

En blanco

Total de votos válidos

Total de votos

Total de abstenciones

Total inscritos
Votos Concejales Porcentaje

$9960 \quad 6+1 \times$ resto $\quad 29.27$

$8924 \quad 6+1 \times$ resto $\quad 26.23$

$2321 \quad 1+1$ x resto $\quad 6.82$

$2049 \quad 1+1 \times$ resto $\quad 6.02$

$1513 \quad 1+1 \times$ resto $\quad 4.44$

$1233 \quad 1 \times$ resto $\quad 3.62$

$1170 \quad 1 \times$ resto $\quad 3.43$

$849 \quad 1$ x resto $\quad 2.49$

$848 \quad 2.49$

$736 \quad 2.16$

$712 \quad 2.09$

$684 \quad 2.01$

$576 \quad 1.69$

393

$390 \quad 1.14$

$182 \quad 0.53$

$156 \quad 0.45$

$144 \quad 0.42$

$1174 \quad 3.45$

$3282960.08^{\mathrm{a}}$

$34018 \quad 62.22^{\mathrm{a}}$

20624

54642

${ }^{\text {a }}$ Porcentajes sobre el total de inscritos. Cálculos sobre la información extraída de La Capital, 29 de abril de 1928 y 11 de mayo de 1928; La Acción, 8 de mayo de 1928. 


\section{Cuadro 8. Elecciones del Concejo Deliberante (11 de noviembre de 1928)}

Listas

Votos Concejales Porcentaje

Unión Cívica Radical Junta Reorganizadora

$12830 \quad 3+1 \times$ resto $\quad 30.40$

Unión Cívica Radical (Comité Nacional)

$11773 \quad 3+1 \times$ resto $\quad 27.89$

Caballeristas

Partido Demócrata Progresista

Comité Hipólito Irigoyen (Cilvettistas)

$10431 \quad 2+1 \times$ resto $\quad 24.71$

Partido Comunista

3.78

Partido Socialista Independiente

3.34

Partido Socialista

Reacción Gremial

1.69

Unión Popular de Rosario

1.39

588

1.14

En blanco

Total de votos válidos

$72.55^{\mathrm{a}}$

Total de votos

40753

$75.12^{\mathrm{a}}$

Total de abstenciones

42200

$24.87^{\mathrm{a}}$

Total inscritos

56171

${ }^{a}$ Porcentajes sobre el total de inscritos. Cálculos sobre información extraída de Santa Fe, 17 de noviembre de 1928; La Acción, 12 y 17 de noviembre de 1928.

listas lograron representantes) y precisamente esta misma circunstancia había dejado a cada grupo en mejores condiciones de negociación con la facción mayoritaria. Nuestra hipótesis es que tal polarización es el resultado concreto e inmediato del doble accionar de una de las facciones yrigoyenistas (el caballerismo) ${ }^{18}$ al introducir una clara interpelación social (obrera) en el discurso político del radicalismo, como de la acción de aquellos mismos agentes a los

${ }_{18}$ Ricardo Caballero fue un político paradigmático en Santa Fe a lo largo de casi medio siglo. Según algunos contemporáneos tuvo un acercamiento al anarquismo en su juventud, pero toda su vida política activa la hizo al interior del radicalismo. Líder rosarino durante la revolución de 1905, primer vicegobernador radical en Santa Fe (1912), diputado nacional (1916), senador nacional en dos ocasiones (1919-1928; 1937-1943). Para un perfil más desarrollado del mismo, véase Videla y Zanella (2005). 


\section{Cuadro 9. Elecciones del Concejo Deliberante (10 de noviembre de 1929)}

Listas

Partido Demócrata Progresista

Unión Cívica Radical Oficialista (Caballeristas)

Unión Cívica Radical Núcleo

Unión Cívica Radical Unificada

Partido Comunista

Partido Socialista Independiente

Partido Socialista

En blanco

Total de votos válidos

Total de votos

Total de abstenciones

Total inscritos

Votos Concejales Porcentaje

$\begin{array}{rlr}13362 & 4 & 33.00 \\ 10739 & 3 & 26.52 \\ 8159 & 2+1 \times \text { resto } & 20.15 \\ 2526 & 1 \text { x resto } & 6.23 \\ 1938 & 1 \times \text { resto } & 4.78 \\ 947 & & 2.33 \\ 811 & & 2.00 \\ 2002 & & 4.94 \\ 38482 & & 68.32^{\mathrm{a}} \\ 40484 & & 71.88^{\mathrm{a}} \\ 15836 & & 28.11^{\mathrm{a}} \\ 56320 & & \end{array}$

a Porcentajes sobre el total de inscritos. Cálculos sobre información extraída de El Orden, 15 de noviembre de 1929 y La Acción, 6 y 15 de noviembre de 1929.

que se interpelaba, los trabajadores rosarinos; a esta articulación le dedicaremos el último apartado.

Un párrafo aparte merece el desempeño de las izquierdas: en principio porque a partir de las reformas del sistema electoral logran representación en el legislativo municipal hasta $1930,{ }^{19}$ es más, no obstante el hiato que impone el golpe de Estado de 1930, retomarán su presencia a partir de $1932 .{ }^{20}$ Son tres los partidos que incluimos en esta caracterización: el Partido Socialista (PS), el Partido Comunista (PC) y el recién organizado Partido Socialista Independiente (PSI). El primero contaba con presencia en la ciudad desde finales del

${ }_{19}$ En primeras elecciones logran un concejal el Partido Socialista Independiente y el Partido Comunista; en las de noviembre de 1929 el PC logra conservar el suyo, no así el PSI. Previamente no se presentaban a las elecciones municipales por no ser estas de sufragio universal. Si bien esta era la postura del Partido Socialista en la coyuntura, este había participado en el pasado en alguna que otra elección municipal (Ternavasio, 1991, 109).

${ }^{20}$ Para la presencia de las izquierdas en el $\mathrm{CD}$ en los años treinta, véanse Fernández y Armida (2000) y Roldán (2012). 
siglo xIx, pero escasamente había obtenido adhesiones tanto a nivel electoral como sindical, el PC (escisión de aquel) estaba iniciando un periodo de crecimiento particularmente sostenido, en buena medida, por su crecimiento gremial (Menotti, 2009); el PSI de muy reciente creación debuta electoralmente en las municipales de 1928 y, según comunistas y radicales, arrastra adhesiones tanto entre los socialistas como algunos votos más cercanos al PDP ${ }^{21}$ (véase cuadro 10).

Un seguimiento del voto de la izquierda establece una clara correlación: mientras mejor desempeño tienen los radicales "obreristas", peor desempeño realizan particularmente el PSI y el Ps. Una excepción (relativa) es la evolución del PC ya que a nivel municipal crece significativamente en una correlación casi estricta con los picos de conflictividad social. ${ }^{22}$

\section{LA CONFLICTIVIDAD OBRERA EN TIEMPOS DE ELECCIONES MASIVAS: TENSIONES SOCIALES Y DISCURSIVAS EN LA POLÍTICA}

El año 1928 fue un momento crucial en la historia del movimiento obrero, no sólo rosarino, sino también argentino (Videla y Menotti, 2013). El ciclo de huelgas que se iniciaron en los puertos santafesinos tuvieron una gran importancia porque marcaron puntos de inflexión en la dinámica del movimiento obrero y en su relación con los principales actores políticos. En este sentido, como sostuvo Roberto Korzeniewicz (1993), las huelgas portuarias de principios de 1928 -que abrieron el camino a nuevas agitaciones urbanas durante todo el año y en el espacio rural pampeano a finales de este- fueron soslayadas hasta hace muy poco por los estudios históricos. Fue precisamente este autor quien llamó la atención acerca de la importancia de la agitada movilización laboral que se inició en 1928 en Rosario. Su análisis abordaba los dilemas de la dirigencia política de la UCR frente al problema que presentaba la clase obrera en cuanto a sus demandas y a su organización. En este sentido, planteó que los gobernantes radicales santafesinos buscaron implementar

${ }^{21}$ Concejo Deliberante de Rosario. Diario de Sesiones. mayo-julio de 1928.

${ }^{22}$ El mismo mes de mayo de 1928 están atravesados por las huelgas urbanas (Videla y Menotti, 2013); noviembre de 1928 por las urbanas y rurales (Ascolani, 2009; Videla y Menotti, 2013), y en julio y noviembre de 1929 la ciudad nuevamente esta convulsionada por la "cuestión obrera" (Alarcón, 2016). 
Cuadro 10. Evolución del voto de las izquierdas, Rosario, 1926-1929

$\begin{array}{lccccc}\text { Partidos } & \begin{array}{c}7 \text { de febrero } \\ \text { de } 1926^{\mathrm{a}}\end{array} & \begin{array}{c}5 \text { de febrero } \\ \text { de } 1928^{\mathrm{a}}\end{array} & \begin{array}{c}29 \text { de abril } \\ \text { de } 1928\end{array} & \begin{array}{c}\text { 11 de noviembre } \\ \text { de } 1928\end{array} & \begin{array}{c}\text { 10 de noviembre } \\ \text { de } 1929\end{array} \\ \text { PC } & 983 & 357 & 1170 & 1411 & 1938 \\ \text { PSI } & & & 1233 & 925 & 947 \\ \text { PS } & 986 & 341 & 848 & 715 & 811 \\ \text { Total } & 1969 & 698 & 3251 & 3051 & 3696\end{array}$

a Elecciones provinciales, la cifra corresponde al total del Departamento de Rosario. Normalmente el distrito de Rosario representa el $90 \%$ del padrón departamental.

Fuentes: La Acción, 6 de febrero de 1928, 8 de mayo de 1928, 17 de noviembre de 1928, y 15 de noviembre de 1929; La Capital, 19 de febrero de 1928 y 11 de mayo de 1928; El Orden, 15 de noviembre de 1929; El Litoral, 10 de marzo de 1930; Santa Fe, 17 de noviembre de 1928.

una serie de políticas para estrechar lazos entre el partido y las organizaciones sindicales; $y$, si bien al mismo tiempo y a nivel general, asumía que estas tuvieron escaso éxito, Korzeniewicz afirmaba que estos hechos sirvieron para marcar "un temprano desarrollo del populismo en la Argentina". Por su parte, Mathew Karush (2002) indagó en la misma línea al analizar, en un marco general y en un más largo plazo, a la dirigencia política radical en Rosario; su enfoque se fijaba en la figura de Ricardo Caballero -uno de los principales protagonistas en las huelgas del año 1928- y su trabajo intentaba demostrar que los radicales se esforzaron por integrar políticamente a los trabajadores en tanto "ciudadanos".

Ahora bien, ya desde los primeros días de 1928, la cuestión político-electoral también presentaba un aspecto complejo. El radicalismo antipersonalista (representado en la provincia por los unificados) desde el año previo estaba en retirada a nivel provincial y nacional. En ese contexto, el yrigoyenista Pedro Gómez Cello decidió postularse para el cargo de gobernador. Para ello tejió una alianza con varios sectores del fragmentado radicalismo en la que resaltaba Caballero (dueño de un particular discurso que combinaba obrerismo con criollismo y nacionalismo), circunstancia que le permitió ganar las elecciones provinciales de febrero. Por otra parte, los comicios nacionales realizados el 1 de abril le dieron un contundente triunfo a Hipólito Yrigoyen, a lo que se suman las elecciones municipales de fines de ese mes en la que los radicales yrigoyenistas desplazan a los demoprogresistas del CD. Finalmente, 
a los pocos días (ya en mayo y en medio de la conmoción de la huelga portuaria y las movilizaciones por el asesinato de la joven obrera Luisa Lallana), Gómez Cello designa a Caballero como jefe de la policía de la ciudad.

En este sentido, no se debe soslayar la expectativa generada en los trabajadores por la vuelta de unos políticos considerados obreristas a la nación, a la provincia de Santa Fe y a la ciudad de Rosario. ${ }^{23} \mathrm{Al}$ mismo tiempo, no se debe dejar de percibir la creciente agitación precedente, iniciada en 1927 por las organizaciones obreras y de izquierda con las manifestaciones de solidaridad referidas a Sacco y Vanzetti, que en la sureña ciudad santafesina y en el territorio provincial en su conjunto, tuvieron una destacada efervescencia y que incluyó también a miembros más radicalizados de la facción caballerista. ${ }^{24}$

El impacto de la conflictividad obrera, particularmente los desafíos que supone la explícita interpelación a los obreros de las facciones radicales -evidentemente la caballerista, pero no sólo esta- hizo que muchos líderes radicales construyeran parte de su legitimidad sostenidos en la táctica de presentarse como representantes de los obreros: José Benjamín Abalos, Jorge Raúl Rodríguez, Alcides Greca y aun el demoprogresista devenido radical José Guillermo Bertotto entre los más visibles. Esta circunstancia impacta concretamente en el estricto ámbito electoral: si bien en las primeras elecciones municipales con el nuevo sistema electoral no aparece de manera tan clara y contundente (a diferencia de la campaña para las elecciones de noviembre), las acusaciones contra el "personalismo" por su incitación a la clase obrera son recurrentes. ${ }^{25}$ Ahora bien, a partir de esa coyuntura y producto directo del accionar de los caballeristas, la "política obrerista" de estos pone distancias entre las facciones yrigoyenistas, y ya desde la mitad del año, estalla otra fractura: se constituye el Núcleo (que pronto adopta el nombre

${ }^{23}$ El vínculo ha sido resaltado, además de los citados Karush, Korzeniewicz y Horowitz, por otros investigadores como Ricardo Falcón, y también en algunas memorias de militantes, como el líder comunista rosarino Florindo Moretti ("Muchos de los portuarios protagonistas de aquella huelga ganada habían también depositado su confianza en el caudillo de la UCR. [se refiere a Yrigoyen]" (Lozza, 1985, p. 273).

${ }^{24}$ El Nativo, 15 de septiembre de 1928.

${ }^{25}$ El periódico prounificado La Acción, en un editorial inmediatamente posterior al sepelio de Lallana, lo dice con todas las letras: "No son pocos los que vaticinan un periodo sumamente agitado, entendiendo que cierta clase de propaganda proselitista ha llevado al ánimo del proletariado el convencimiento absoluto de que el triunfo del personalismo había de abrir de par en par las puertas a cuanto reclamo proviniese de la clase trabajadora." La Acción, 10 de mayo de 1928. 
UCR Junta Reorganizadora) compuesta por aquellos mencionados más arriba (muchos de ellos antiguos defensores de la vetada Constitución de 1921) y por talante político más cercanos al reformismo liberal que las huestes caballeristas. La nueva división partidaria se consolidó en noviembre, cuando Caballero se presentó a las elecciones municipales con una lista propia, por fuera de las fuerzas yrigoyenistas.

Por otra parte, no podemos dejar de notar que las elecciones de noviembre suponen un claro corrimiento discursivo, si no hacia la izquierda, sí hacia una retórica radical-populista y obrerista de buena parte del electorado. En estos términos, el relativo debilitamiento de las orientaciones de la izquierda orgánica (PS, PSI) no supone que haya un retroceso en las opciones discursivamente (y prácticamente) favorables a la clase obrera; en este sentido la magnitud del voto caballerista (y aun la relativa concentración de algunas facciones radicales tras este), en un contexto claramente atravesado por la conflictividad obrera, no puede más que interpretarse como ejemplificación de una extensa opinión obrerista en la ciudad, es más, postulamos que debe precisamente considerarse como parte de la extensión e iniciativa de la clase obrera rosarina sobre el espacio público. En este sentido, mirado desde la clase obrera, las disputas de los "personalistas" con los "antipersonalistas" y los demoprogresistas, permitió que los trabajadores tuvieran un margen de espacio para elevar sus reclamos, mostrar su fuerza en la calle sin ser reprimidos y sentarse a negociar con un frente empresario poderoso.

Por otra parte, en el plano de lo estrictamente partidario, la situación supuso un claro desafío para casi todos los partidos: el "obrerismo" era indudablemente uno de los ejes por los cuales podemos tratar de explicar el intrincado panorama de las facciones radicales: ya ha sido destacado por Karush su efecto para entender las disputas al interior del radicalismo (en particular como estigma atribuido a los policromos yrigoyenistas por las distintas facciones que en ocasiones confluyen como antipersonalistas), pero también recorren las filas de aquellos. En este sentido, es evidente que la formación del Núcleo (integrada por conspicuos "obreristas"), en medio de otro ciclo de huelguistas, está marcada por las prácticas de acercamiento (más estrictamente, por el relativo éxito de estas) del caballerismo a la clase obrera. Ahora bien, la misma facción caballerista tenía ese mismo conflicto; evidencia de ello es la iniciativa de uno de sus grupos sindicales adictos (en general ferroviarios articulados alrededor de la publicación El Nativo y la asociación cultural "Solidaridad Social") de crear un partido radical obrero (nacionalista 
popular, latinoamericanista, cooperativista, internacionalista, y por tanto reinvindicador de la revolución rusa, en algún sentido clasista y en particular furibundamente yrigoyenista) (Müller, 2008). Por otra parte, que el líder de la facción no tomara este camino también es un indicador de hasta dónde llegaban los límites de una construcción política que no asumiría plenamente la condición obrera de su identidad política.

Por otra parte, este mismo grupo sindical caballerista ejemplifica las tensiones que recorrían a la izquierda local: si bien no podemos confirmarlo plenamente parece evidente que los "nativistas" formaban parte de una facción al interior del ps que en la coyuntura migró al caballerismo rosarino. ${ }^{26}$ Es que, en general, todas las orientaciones ideológicas de izquierda percibían el impacto de la política caballerista y por tanto se encargaban de advertir contra ella a los obreros. En este sentido, es interesante cómo La Internacional (uno de los órganos de prensa más importantes del PC) debía señalar el diferencial que suponía la gestión de Caballero respecto de los conflictos: "Es importante, a los fines de la lucha que se desarrolla y de su victoria futura, que el proletariado esté en guardia contra las maniobras y especulaciones demagógicas de la burguesía caballerista, intensificando su acción de clase y acentuando su independencia absoluta como tal." ${ }^{27}$

Por otra parte, casi paradojalmente, el discurso popular-obrerista de las facciones yrigoyenistas (y más radicalmente de la facción caballerista) también cercaba las posibilidades discursivas del PDP; en este sentido, es evidente que, ni dentro de los recursos retóricos, pero tampoco en el tono de sus apelaciones discursivas, predominaron el estilo altisonante, "plebeyo", populista de algunas facciones radicales, más aún, en el plano de los tópicos del discurso político, era evidente que uno de los más transitados por los demoprogresistas, el del reformismo político (encarnado en la vetada Constitución de 1921) ya no tenía la efectividad (ni tampoco la centralidad) de los años previos (Mauro, 2013, p. 87). En este sentido, la escasa presencia -desde la retórica

${ }^{26}$ Isidro Oliver (militante socialista cordobés, exdiputado en esa provincia) señala que para esa época se inicia en Rosario y Córdoba una tendencia "más universalista" (producto de lecturas tales como las de Tolstoy, Gorki, Marx y Proudhon): "Estos innovadores reconocían como jefe a Ricardo Caballero, quien en Rosario actuó con los grupos anarquistas, en lamentable confusión, pues los tales renovadores resultaron vulgares 'políticos criollos' y de lo más reaccionarios, creadores de un misticismo político que encontró acomodo en la Unión Cívica Radical de esa época. El atraso político del pueblo ha sido y es la causa de grandes males." (Oliver, 1951, p. 124). Cursivas mías.

${ }_{27}$ La Internacional, 28 de julio de 1928. 
política- del discurso social en el PDP pudo haber sido uno de los motivos de la sangría de votos (y previamente de dirigentes) que se hizo notable en febrero de $1928 .^{28}$

\section{REFLEXIONES FINALES}

Como vimos, es evidente que el nuevo mecanismo electoral produce novedades en el sistema de partidos local, en principio por la presencia notable, claramente mayoritaria, que tendrán de aquí en adelante en el legislativo municipal las diversas vertientes que componen el heteróclito radicalismo; como otras instancias legislativas será el canal en el cual confluyan (contradictoriamente) a dar vida a una identidad política tan extensa que puede albergar en su seno buena parte de las tensiones políticas (y aún sociales) de la Rosario de fines de la década de los veinte.

Por otra parte, ya se ha señalado que otra novedad es la pérdida (relativa) de la hegemonía demoprogresista. No obstante, la situación se verá morigerada por la aplicación de la representación proporcional que estos mismos habían evadido a nivel municipal (en flagrante contradicción con sus postulados generales expresados en fallida Constitución de 1921) hasta que la inminencia de la reforma electoral lo hizo impostergable. Pero la representación proporcional también dio vida a otras expresiones del arco ideológico, en particular a unas pequeñas pero dinámicas expresiones de izquierda, que sin dudas lograron articular intereses sociales y políticos de una manera que todavía no podemos más que postular.

Otro componente, tal vez menos novedoso, es que el nuevo sistema electoral deja ya definitivamente fuera de las ecuaciones político-electorales a los extranjeros, no solamente porque su número fuera ahora claramente insignificante en el nuevo padrón (aunque sugerimos que ya lo venía siendo en el antiguo padrón de contribuyentes), sino porque no parece que esta circunstancia sea motivo para que las agrupaciones políticas tomen el tema como parte significativa de sus agendas, tal como lo había sido en el pasado

${ }^{28}$ En este sentido, es notable el salto de algunos líderes rosarinos a la facción yrigoyenista que luego conformaran el Núcleo, Alberto Mazza uno de ellos, pero seguramente el más impactante es José Guillermo Bertotto, precisamente uno de los pocos demoprogresistas caracterizados por el alto contenido social de su discurso. 
reciente. Es más, contrasta con la circunstancia que estos (los extranjeros) no han decaído en su número ( $45 \%$ de la población rosarina lo era); pero la pregunta sobre quién asume su representación es sin dudas parte de una agenda de investigación posterior. Al presente sólo indicios nos hacen pensar que tal vez fueran las organizaciones gremiales y/o las territoriales (las nacientes asociaciones vecinales) donde encontraran respuestas a sus intereses.

Visto desde la dinámica temporal de muy corto plazo, la novedad más evidente para el sistema político municipal es la rapidísima transformación que sufren casi todos los actores políticos preexistentes: con la excepción parcial del PDP (que por otra parte ya tenía una posición dominante), las agrupaciones electorales preexistentes se reconfiguran o desaparecen en menos de un año. Por un breve momento pareciera que el nivel municipal de la política va adquiriendo una fisonomía particular y distintiva: un ámbito donde se procesan casi formalmente un primer nivel de las internas del partido mayoritario al tiempo que habilita la aparición de una estructura de partidos "orgánicos" más extensa y compleja (tanto a la derecha como a la izquierda del arco ideológico). No obstante, muy pronto el sistema de partidos municipal se asemeja más al nivel provincial, y una evidencia de ello es que los tópicos que lo recorren en la coyuntura (fundamentalmente el tema de "obrerismo" radical) se convierten en uno de los ejes articuladores de los posicionamientos partidarios.

Finalmente, respecto de nuestra preocupación inicial por la articulación entre conflicto obrero y política municipal, comprobamos que, en el ánimo de la masa obrera, la perspectiva de la vuelta de los yrigoyenistas incidió al crear un "clima de oportunidad" para sus reclamos, que se reforzó por el comportamiento puntual de alguna de sus facciones. Pero, a su vez, provocó que el enfrentamiento de clases profundizara las diferencias internas del radicalismo, tensionándolo hasta la ruptura partidaria, pero no ideológica. En este sentido, postulamos que, para acercarnos a una explicación, hay que pensar "radicalmente" (es decir dentro de la lógica de la identidad partidaria) y que, por tanto, aun para sectores del radicalismo yrigoyenista con cierta orientación social (J. R. Rodríguez, el "Núcleo", por ejemplo) el movimiento obrero era "exterior" a su propia experiencia política y no integrable (relativamente) en el entramado de la propia identidad. En este sentido, estos sectores estarían todavía encorsetados por una matriz ideológica que no podía pensar en un movimiento obrero "radical" como parte de una identidad más extensa. El caballerismo, por lo menos en la coyuntura, estaría indicando que el cami- 
no no era intransitable, pero suponía asumir plenamente tanto tareas prácticas (ya sean las de intervención estatal, si se estaba en lugares de decisión, o las más propias de la militancia sindical, a nivel de la acción colectiva), como también las consecuencias de los conflictos derivados de una estrategia donde la conflictividad social se articulaba con la política, derrotero que el radicalismo, en general, no estaba dispuesto a emprender más allá de la disposición favorable, o no, de los trabajadores.

\section{LISTA DE REFERENCIAS}

Aguilar Rivera, J. A. (1998). La nación en ausencia: primeras formas de representación en México. Política y Gobierno, 5(2), 423-457. Recuperado de http://cide.repositorioinstitucional.mx/jspui/handle/1011/627

Alarcón, N. (2013). Los comerciantes minoristas de Rosario en pos de su identidad: defensa gremial, relaciones intercorporativas y política (1894-1909). Cuadernos del CIESAL, 12, 75-99. Recuperado de http://www.fcpolit.unr.edu.ar/wp-content/ uploads/05-Alarc\%C3\%B3n.pdf

Alarcón, N. (2016). Corporaciones empresarias, política y conflicto obrero en los prolegómenos de la crisis. (Tesis de licenciatura inédita). Universidad Nacional de Rosario, Rosario.

Ascolani, A. (2009). El sindicalismo rural en la Argentina. De la resistencia clasista a la comunidad organizada (1928-1952). Buenos Aires: Universidad Nacional de Quilmes.

Bonaudo, M. (2006). Ciudadanos, contribuyentes y productores en pos de sus derechos (1880-1912). En M. Bonaudo (comp.), La organización productiva y política del territorio provincial (1853-1912) (pp. 189-215). Rosario: Prohistoria.

Bonaudo, M. (2008). Aires gaditanos en el mundo rioplatense. La experiencia de los jefes políticos y el juicio por jurados en tierras santafesinas (segunda mitad del siglo XIX). Revista de Indias, LXVIII(242), 255-280. DOI: 10.3989/revindias.2008. i2 42.642

Botana, N. (1985). El orden conservador. Buenos Aires: Hyspamérica.

Carrizo, B. (2005). Las tensiones en la trama notabiliar y la participación electoral del radicalismo. Santa Fe, 1910-1912. Ponencia presentada en las X Jornadas Inter Escuelas-Departamentos de Historia, Rosario, Argentina.

Castro, M. (2012). El ocaso de la república oligárquica. Poder, política y reforma electoral, 1898-1912. Buenos Aires: Edhasa. 
Cecchini de Dallo, A. M. (1991). Santa Fe. La elección provincial de 1912. Su importancia como coyuntura política. Revista de la Junta de Estudios Históricos de Santa Fe, LVII, Santa Fe.

Ensinck, O. (1970). El régimen municipal en la provincia de Santa Fe. En AA. VV., Historia de las instituciones de la Provincia de Santa Fe (T. III, pp. 140-171). Santa Fe: Comisión Redactora de la Historia de las Instituciones de la Provincia de Santa Fe.

Fernández, S. y Armida. M. (2000). Una ciudad en transición y crisis (1930-1943). En Alberto Pla (dir.), Rosario en la historia (de 1930 a nuestros días) (pp. 23-151). Rosario: UNR Editora.

Horowitz, J. (2015). El radicalismo y el movimiento popular (1916-1930). Buenos Aires: Edhasa.

Irurozqui, M. (2007). Los mil y un senderos de la ciudadanía. Reflexiones y propuestas historiográficas sobre el desarrollo de la ciudadanía en América Latina. En P. García Jordán (ed.), Estado, región y poder local en América Latina, siglos XIX-XX. Algunas miradas sobre el Estado, el poder y la participación política (pp. 81-114). Barcelona: Publicacions I Edicions de la Universitat de Barcelona.

Karush, M. B. (2002). Workers or citizens. Democracy an identity y Rosario, Argentina (1912-1930). Albuquerque: University of New Mexico Press.

Karush, M. B. (2006). Radicalismo y conflicto obrero urbano. 1912-1930. En O. Videla (dir.), El siglo xx. Problemas sociales, políticas de Estado y economías regionales (19121976) (pp. 39-84). Rosario: Prohistoria y La Capital.

Korzeniewicz, R. (1993). The labor politics of radicalism: The Santa Fe crisis of 1928. Hispanic American Historical Review, 73(1), 1-32. DoI: 10.2307/2517628

Lozza, A. M. (1985). Tiempo de huelgas. Los apasionados relatos del campesino y ferroviario Florindo Moretti sobre aquellas épocas de fundaciones, luchas y serenatas. Buenos Aires: Anteo.

Martín, M. del C. P. (2012). Iglesia católica, cuestión social y ciudadanía. Rosario-Buenos Aires, 1892-1930. (Tesis de doctorado inédita). Universidad Nacional de Rosario, Rosario.

Mauro, D. (2013). Reformismo liberal y política de masas. Demócratas progresistas y radicales en Santa Fe (1921-1937). Rosario: Prohistoria.

Menotti, P. (2009). Maximalismo y organización. El papel de los comunistas en el movimiento obrero santafesino frente a las crisis y conflictos sociales de 1917/21 y 1928. Ponencia presentada en las XII Jornadas Interescuelas/Departamento de Historia, Bariloche, Argentina.

Monsalvo Mendoza, E. (2009), Ciudadanía y elecciones en el mundo hispánico. Elementos para un debate historiográfico. Historia Caribe, 15, 159-183. Recuperado de 
http://investigaciones.uniatlantico.edu.co/revistas/index.php/Historia_Caribe/ article/view/99/61

Moyano, J. (2006). Espacios municipales y liberalismo conservador en México y Argentina. Un ensayo comparativo a partir de la legislación. 1876-1912. Cuadernos de Historia, 8, 43-71. Recuperado de https://revistas.unc.edu.ar/index.php/ cuadernosdehistoriaeys/article/view/9925/10600

Müller, M. (2008). El Nativo de Rosario. Periódico antiimperialista, obrero, nacionalista y radical. Los sentidos del nacionalismo en los confines de los años 20. En S. Fernández y O. Videla (comps.), Ciudad oblicua. Aproximaciones a temas e intérpretes de la entreguerra rosarina (pp. 39-54). Rosario: La Quinta Pata \& Camino.

Oliver, I. (1951). El socialismo en el interior argentino. Rosario: Editorial El Sol.

Ponce de León Atria, M. (2015). Competencia política y fraude electoral en Chile, 1912-1925, Nuevo Mundo Mundos Nuevos. DoI: 10.4000/nuevomundo.68264

Privitellio, L. de (2003). Vecinos y ciudadanos. Política y sociedad en la Buenos Aires de entreguerras. Buenos Aires: Siglo XXI.

Privitellio, L. de (2011). Los límites de la abstracción: individuo, sociedad y sufragio femenino en la reforma constitucional de San Juan (1927). PoLHis, 4(7), 59-77. Recuperado de: http://www.historiapolitica.com/datos/boletin/polhis7_privitellio. pdf

Ragas Rojas, J. (2006). Clío en las urnas. La historiografía electoral sobre el Perú. Estado de la cuestión y guía bibliográfica (1810-1930). Elecciones, 6, 243-272. Recuperado de http://www2.congreso.gob.pe/sicr/cendocbib/con2_uibd.nsf/A08A88BAB743A6F4052575A800828DE7/\$FILE/urnas.pdf

Rock, D. (1977). El radicalismo argentino, 1890-1930. Buenos Aires: Amorrortu.

Roldán, Diego (2012). Dos instantáneas locales del ciclo liberal reformista. El municipio de Rosario, 1920-1935. Revista Estudios del ISHIR, 2(3), 101-116. Recuperado de http://historiapolitica.com/datos/biblioteca/santafe_rold\%C3\%A1n.pdf

Ternavasio, M. (1989). Sistema político y organización municipal. Santa Fe y la crisis régimen oligárquico. Anuario, 13, 401-436. Rosario, Escuela de Historia. Universidad Nacional de Rosario.

Ternavasio, M. (1991). Municipio y política, un vínculo conflictivo. (Tesis de maestría inédita). Flacso, Buenos Aires.

Ternavasio, M. (1996). Municipio y representación local. Santa Fe: 1900-1920. En J. César Melón Pirro y E. Pastoriza (eds.), Los caminos de la democracia. Alternativas y prácticas políticas, 1900-1943 (pp. 183-199). Buenos Aires: Biblos.

Vidal, G. (2000). El Partido Demócrata y sus tensiones internas. Diferentes perspectivas sobre ciudadanía y participación. Córdoba 1922-1925. Cuadernos de 
Historia, 3, 169-206. Recuperado de: https://revistas.unc.edu.ar/index.php/ cuadernosdehistoriaeys/article/view/9865/10549

Videla, O. y Zanella, E. (comps.) (2005). Historia y política. Cuestión social, radicalismo y revisionismo en Ricardo Caballero. Buenos Aires: Imago Mundi.

Videla, O. y Menotti, P. (2013). Las huelgas de los estibadores portuarios en el sur santafesino en 1928. Sociohistórica. 32, 1-31. Recuperado de https://www.sociohistorica.fahce.unlp.edu.ar/article/view/SH2013n32a04

\section{OTRAS FUENTES}

Concejo Deliberante de Rosario (1927 a 1930). Diario de Sesiones.

Provincia de Santa Fe. Cámara de Diputados (1926 a 1927). Diario de Sesiones.

Provincia de Santa Fe. Cámara de Senadores (1926 a 1927). Diario de Sesiones.

Provincia de Santa Fe (1928). Ley Orgánica de Municipalidades. En Códigos y leyes vigentes en la provincia de Santa Fe. Rosario: Librería de M. Álvarez.

Provincia de Santa Fe (1932). Constitución de la Provincia de Santa Fe. Santa Fe: Imprenta de la Provincia.

\section{Hemerografía}

La Acción, Rosario, 1927-1929.

La Capital, Rosario, 1927-1929.

El Nativo, Rosario, 1928-1929.

La Internacional, Buenos Aires, 1928.

Santa Fe, Santa Fe, 1928-1929.

El Orden, Santa Fe, 1928-1929.

El Heraldo, Rosario, 1928.

El Litoral, Santa Fe, 1930. 